\title{
Urban transformative capacity: From concept to practice
}

\author{
Marc Wolfram, Sara Borgström, Megan Farrelly
}

Published online: 22 March 2019

\begin{abstract}
Urban transformations form a central challenge for enabling global pathways towards sustainability and resilience. However, it remains unclear what kind of capacity is needed to deliver urban change that is actually transformative. Against a backdrop of current claims and efforts to achieve urban transformations, this special issue reviews the relational concept of urban transformative capacity and how it can inform novel approaches in research, policy, and practice. Drawing on seven papers analyzing diverse empirical contexts, we identify four requirements that should guide future action: (1) foster inclusion and empowerment as prerequisites, (2) close the intermediation gap and strengthen the role of local academia, (3) challenge and reinvent urban planning as a key arena, and (4) enhance reflexivity through novel selfassessment techniques. Overall, current levels of urban transformative capacity are assessed as very low, making its development a high-priority objective for all stakeholders, but for planning and research policy in particular.
\end{abstract}

Keywords Cities · Co-production ·

Multi-level governance - Sustainability transition .

Transformative capacity · Urban transformation

\section{INTRODUCTION}

Urbanization forms a key sustainability challenge for humanity since urban areas and processes profoundly affect the life support systems of our planet, as well as human liveability (Groffman et al. 2017; Elmqvist et al. 2018). Principal global problems such as biodiversity decline, climate change, food and water security, energy supply, public health, and social justice are not only wicked, but essentially urban (Grimm et al. 2008), and this will be further accentuated in the future: Projections estimate that by 2050 more than two-thirds of the global human population will live in urban areas (UN DESA 2018). This overall trend includes major regional variations ranging from rapid urbanization in South East Asia and Africa, to stagnation and also shrinkage in Europe and East Asia, and thus the need for differentiated responses (ibid). However, under all regional conditions it will be pivotal to develop holistic approaches addressing a multitude of interconnected urban actors, practices, and places in order to achieve the necessary global-level sustainability transformations (Frantzeskaki et al. 2017; Acuto et al. 2018; Romero-Lankao et al. 2018).

Corresponding calls in science, policy, and practice to foster "transformative" urban change have intensified in recent years. From the UN 2030 agenda (UN 2015) and the New Urban Agenda (UN 2016), to the recent IPCC special report SR15 (IPCC 2018) and the CitiesIPCC research and action agenda (CitiesIPCC 2018), as well as a range of city-driven or city-targeted initiatives (such as C40 cities, Carbon Neutral Cities Alliance, 100 Resilient Cities, Covenant of Mayors, WWF One Planet Cities, etc.) and a plethora of local civil-society-led initiatives: Diverse actors are demanding or already developing capacity and actions that target urban sustainability transformations.

However, despite such multi-level actions, it remains far from clear what kind of capacity can actually deliver urban change towards sustainability that is transformative, i.e., disrupting current pathways by deeply and radically altering existing urban structures, cultures, and practices (Wolfram et al. 2016; Frantzeskaki et al. 2018). The scientific debate about transformative capacity and its constituents has so far remained fragmented, and often also lacks reference to urban contexts and their particularities 
(Olsson et al. 2010; Marshall et al. 2012; Moore et al. 2018). Correspondingly, also funding agencies that already offer dedicated support for research and capacity development aimed specifically at urban transformations do not provide comprehensive orientation yet, even though they appear to converge over some criteria (cf. Iwaniec et al. 2019).

In order to inform an emerging urban change agenda designed and implemented by individuals and organizations at all scales, there is thus an urgent need to explore and explain the transformative capacity required for this in more depth. This special issue takes up this challenge and aims to take stock regarding the concept of urban transformative capacity (Wolfram 2016), and to move on from the theoretical debate towards identifying practices that can help to develop such capacity. For this purpose, we ask the following three guiding questions: (1) What are critical components of urban transformative capacity, and how do they interact? (2) How can urban transformative capacity be consistently assessed in different world regions, countries, and places? (3) How can urban transformative capacity be developed purposefully in practice to foster radical urban change towards sustainability and resilience?

\section{URBAN TRANSFORMATIVE CAPACITY: A CONCEPTUAL BASELINE}

The idea of transformative capacity as a distinct complex system property originates from research using resilience theory to study social-ecological system (SES) dynamics. Since the early formulation of resilience theory in the 1970s (Holling 1973), the focus in this field had been to understand how to enable SES to anticipate and cope with (external) changes that could undermine their structure, identity, and functions, and ultimately lead to irreversible damages in both ecological sustainability and human living conditions. Consequently, this debate first centered on adaptive capacity as an umbrella concept for capturing generic capabilities that could strengthen the resilience of SES such as (1) learning to live with change and uncertainty; (2) nurturing diversity and social-ecological memory for reorganization and renewal; (3) combining different types of knowledge for learning (experiential-, experimental-, process-, structural-, functional-); and (4) creating opportunity for self-organization and flexible problem solving across scales (Folke et al. 2003).

Corresponding actions were also proposed to develop strategies aimed at building adaptive capacity, i.e., adaptive (co-)management (Folke et al. 2002; Olsson et al. 2004). However, empirical insights increasingly suggested that adaptation could turn out to be a detrimental strategy if the existing system displayed characteristics of lock-in as well as external and internal stress factors that would ultimately impede effective adaptation, thus making crisis and collapse inevitable. Such situations would thus require transformative capacity (TC) instead, i.e., the ability to "create a fundamentally new system when ecological, economic, or social (including political) conditions make the existing system untenable [...]" (Walker et al. 2004, p. 4).

Motivated by various symptoms of the (urban) sustainability crisis, similar propositions have also emerged in other scientific fields, offering diverse ideas of what characterizes TC, and how it differs from adaptive capacity (Healey 1998; Coleman and Chiasson 2002; Innes and Booher 2003; Moulaert et al. 2005; Halpin and Daugbjerg 2008; Olsson et al. 2010; Dolata 2013; Griffith 2014; Ardoin et al. 2015; Rauschmayer et al. 2015). While encompassing all adaptation requirements, these propositions commonly identify two additional capabilities that are critical for transformations: To be able to actively disrupt and dismantle existing systems, and to simultaneously create and build up viable alternatives (Moore et al. 2018).

Drawing on this debate Wolfram (2016) suggested an integrated framework to inform analytical as well as intervention approaches. The framework maps out 10 interdependent key components (C1-10) of TC and 60 factors that identify requirements for their development (Wolfram, p. 127). Crucially, this framework refers transformative capacity to urban stakeholders, places, and processes-both as a capacity source and subject of transformation. At its core is therefore an emphasis on forms of urban agency and institutions, both place-based and cross-scale, and their interweaving through social learning (Fig. 1): Inclusive and multi-form governance (C1) accounts for broad stakeholder involvement, diversity of formal and informal interactions, as well as effective intermediation; Transformative leadership (C2) asks for individuals in the public, private, and civil society sectors who lead through articulating shared visions, motivating engagement and shaping collaborative processes; Empowered communities of practice (C3) identifies in how far resources are accessible and conditions of autonomy provided for such communities to meet social needs.

These agency-focused components need to engage in four TC development processes (C4-7) that include using systems analysis to understand change dynamics and path dependencies (C4), sustainability foresight, i.e., normative participatory visioning and alternative scenario designs (C5), practical experimentation of communities with novel solutions (C6), and the embedding of effective sustainability innovations, e.g., through resource provision or regulations (C7). Social learning practices and methods (C8) form the vital component required to feed outcomes of all four processes back into the articulation of governance, leadership, and community empowerment (C1-3), 


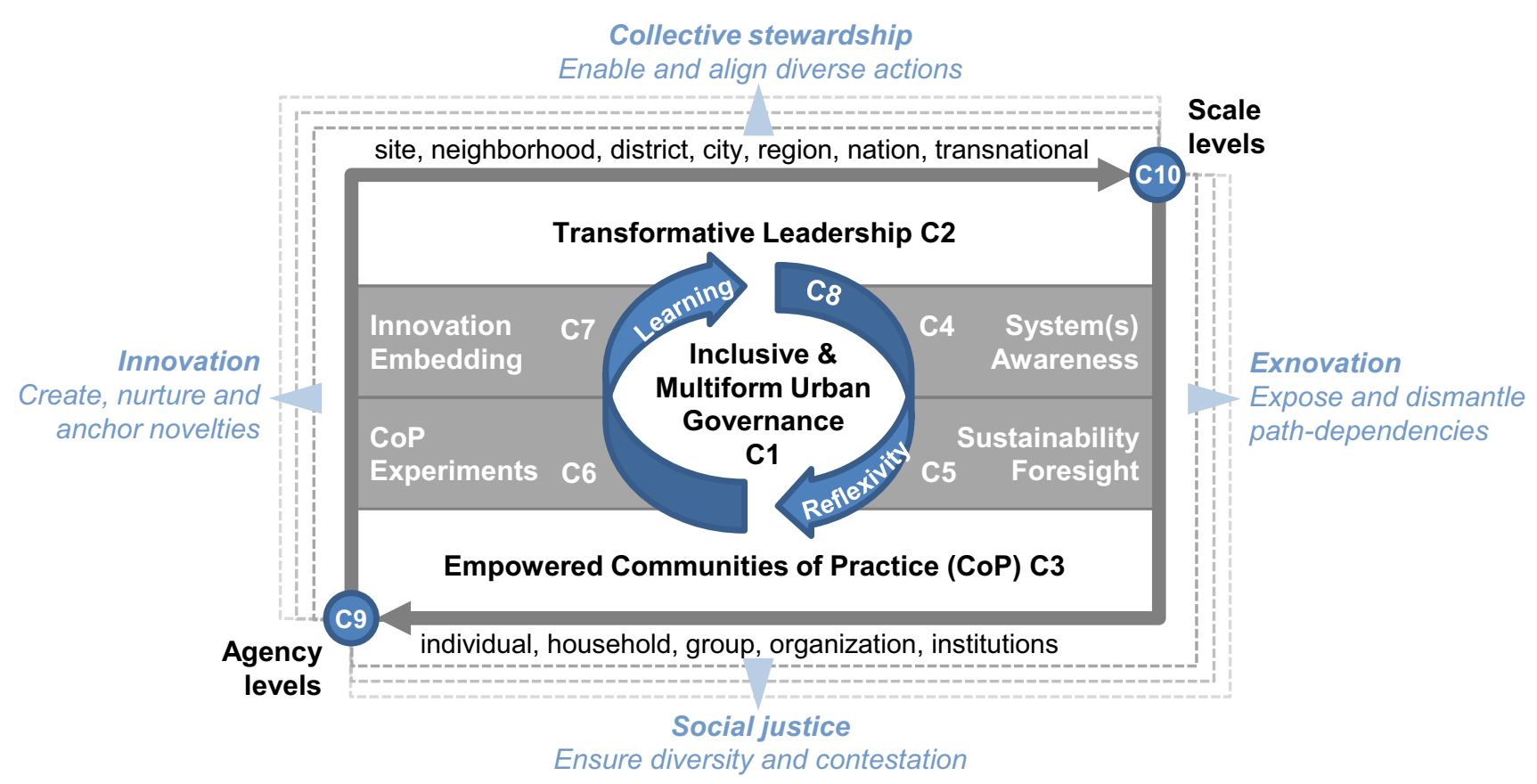

Fig. 1 Overview: interdependent components and targeted outcomes of urban transformative capacity. (cf. Wolfram 2016-modified)

e.g., through collective reflexivity and monitoring system change. Most importantly, the urban TC framework also accounts for critical relational dimensions, i.e., whether the scale levels (local to global-C9) and agency levels (individual, household, organization, association-C10) needed for system change are effectively involved.

Various authors have meanwhile discussed interpretations and definitions of TC that largely align with this framework, but partly also suggest further clarifications regarding its ontological assumptions and provisions for guiding action. This concerns mainly the underlying relational conception of structure/agency and space/materiality, as well as the role of power, dynamics, and normativity in building urban TC.

First of all, the concept of urban TC draws on a relational ontology, i.e., such capacity is not an attribute of individual actors, but results from contingent interactions between distributed agency in a given institutional setting (Kuenkel 2019). This perspective implies that, while institutions have both enabling and constraining effects on actors, they also remain shapeable through institutional work performed by actors that manage to realign rules, knowledge, and resources (Sewell 1992; Lawrence et al. 2009). As illustrated by frequent accounts for particular forms of agency that effectively achieve institutional change, such as transformative leadership, institutional entrepreneurship, or shadow networks (Westley et al. 2013; Moore et al. 2018), these involve actors who occupy multiple positions, change positions, and/or develop boundary-spanning relations (Grillitsch 2017). Inversely, where all principal stakeholders fail to develop such forms of agency and interaction, urban TC and actual change remain necessarily limited (Newton et al. 2017).

Moreover, this relational ontology also conceives of such agency and interaction forms as shaping and shaped by space and materiality (Thrift 1996; Murdoch 2006). Both socio-ecological and socio-technical system scholarship forcefully underline the co-constitution of actors and institutions in relation to multi-scalar ecosystems and/or human artifacts and their spatial configuration (Gunderson and Holling 2002; Geels et al. 2012; Hansen and Coenen 2014). Thus, if landscapes, infrastructures (green, blue, gray), buildings, or vehicles are integral to the systems of concern, the agency and institutions required for transforming them need to reflect this in cognitive, normative, and practical terms. Transformative capacity may thus vary substantially with its spatial-material constituents, considering, e.g., on the one hand how local administrative perimeters frequently diverge from pertinent ecosystem boundaries (i.e., limiting TC), and how multi-level "smart city" coalitions embrace various infrastructure systems on the other (i.e., enhancing TC). In each case, urban change becomes framed in a particular way by inscribing spatial and material configurations into actor positions and interaction forms-not necessarily supporting sustainability. This is equally why urban place has a key role to play in developing TC: Components such as system awareness and the recognition of deficits (social needs), governance networks and community bonds, as well as brokerage and boundary-spanning are essentially place-mediated or even 
place-enabled, strongly affecting actor perceptions of impact, meaningfulness, and desirability of transformations (Marshall et al. 2012). As Ziervogel et al. suggest (2016, p. 2), urban TC thus needs to enable to review and redesign such assemblages by creating "awareness of and a reconnection to the visible systems, both natural [...] and human-made [...], that support our daily well-being." This demands to assess transformative agency and processes also in terms of their spatial-material relations-and the value orientations these support.

Second, the above ontological conception of transformative capacity closely aligns with relational understandings of power and their application to contexts of sociotechnical transitions and planning (Avelino and Rotmans 2011; Avelino and Wittmayer 2016; Avelino 2017; Metzger et al. 2017). Interpreting power as the "(in)capacity of actors to mobilize resources and institutions to achieve a goal" (Avelino 2017, p. 507) suggests that in reverse, the notion of urban TC corresponds to the type of power that effectuates deep and holistic urban change, resulting from particular forms of agency and interactions in a given institutional and spatial-material setting. This equivalence is very helpful to underline that developing urban TC is always and necessarily political and thus subject to contestation and social struggle: Whose urban future will become reality is mediated through urban transformative capacity. Attention should therefore be paid to whether practices of developing TC serve to depoliticize urban change or to perpetuate social, ecological, and economic injustices through selective dis-/empowerment. For this reason, Gilliard et al. (2016) also caution against a reliance on socio-technical or social-ecological system frameworks and related intervention formats (transition management, adaptive management) since these imply a tendency to neglect the contingent micropolitics and social struggles that shape transformations-often beyond the systems primarily considered (Gilliard et al., p. 259). Rather than striving to control through consensus building and management techniques, developing urban TC should thus aim to nurture and harness both diversity and contestation in order to enable justice.

Third, there are various assumptions about the drivers and dynamics of transformations that have implications for setting priorities and devising practical strategies when developing urban TC. Transformative change is often understood as deliberate and conscious, thus framing transformation primarily as a response to the aggravating sustainability crisis (Moore et al. 2014; Ziervogel et al. 2016). However, this is not exclusively so: Transformations could be intended, but may equally be emergent or forced externally, or a result of such dynamics combined. This demands to address different drivers that simultaneously foster the deconstruction of existing systems and the construction of novel ones: There is no single transformation pathway (Wilson et al. 2013; Griffith 2014). Furthermore, transformations do also not occur as one major step but involve typical phases in which the relation between existing and novel configurations shifts (such as pre-development, take-off, acceleration, and stabilization-van Driel and Schot 2005; Chapin et al. 2010; Westley et al. 2011). This suggests that developing urban TC requires to combine and prioritize different strategic purposes according to a given transformation stage. Hölscher et al. (2018) therefore even distinguish between different capacities: (1) stewarding (strengthening system knowledge and self-organization); (2) unlocking (revealing and breaking down existing structures); (3) transforming (creating and embedding novelties); and (4) orchestrating (coordinating multi-actor processes and shaping opportunity contexts). TC development thus needs to address these different purposes and adopt time- and context-specific strategies that foster both system exnovation and innovation (Heyen et al. 2017).

Fourth, transformations may also turn out to move further away from sustainable pathways, i.e., the conception and development of urban TC should always be explicit about its normative orientations (cf. O'Brien 2012; Tàbara et al. 2018). Most propositions about TC effectively result from concerns for sustainability and thus already incorporate a number of provisions supporting its core values and principles (e.g., regarding inclusion and justice, knowledge and value diversity, holistic thinking, long-term foresight). This does, however, not preclude that urban TC may in practice also develop in pursuit of more or less unsustainable changes, reflecting forms of agency and institutions that embrace other value propositions. Applied as an analytical framework the concept thus enables a critical assessment that lays open such variations-but used as a guide for developing capacity it clearly strives to support just sustainability transformations.

In short, the above discussion provides a conceptual baseline for our exploration of how urban transformative capacity is currently developed and assessed in practicedrawing on the different analytical lenses and empirical subjects contributed by the authors in this special issue. It acknowledges that urban TC forms a qualitative and contingent measure of urban system dynamics describing a set of key parameters concerning actors, institutions, physical environs, and their interaction processes. As such it depicts an evolving collective ability to conceive of, prepare for, initiate and perform path-deviant urban change-ideally towards sustainability - and thus offers novel perspectives for shaping intervention strategies that use multiple leverage points simultaneously and sequentially. 


\section{OVERVIEW OF CONTRIBUTIONS}

The contributions brought together in this special issue were selected from an open call for abstracts launched in February 2017. Based on the editorial concept for this selection, all authors have developed their articles through several rounds of feedback, thus strengthening the common overall epistemological concern for exploring urban transformative capacity in practice while covering a complementary focus and diverse empirical contexts. The contributions are organized starting from those examining challenges for developing urban TC, tracing deficits and requirements as they appear in practice, towards those focusing on interventions that potentially help to effectively nurture and co-produce urban TC or critical components thereof. In the following, a brief synthesis of each paper is provided, highlighting their core findings and conclusions for science, policy, and practice. Linkages between individual papers are further explored in the discussion of key findings below.

Drawing on the broadest empirical account in this special issue (400 urban sustainability initiatives from across the globe), Castán Broto et al. (2019) recognize only weak signals of urban TC in practice. The authors assess that most components of the urban TC framework (Wolfram 2016) appear to be present in only $10 \%$ or less of the cases. The highest incidence is shown for a social needs focus, inclusive and diverse governance modes, and community empowerment. Across the range of sustainability challenges addressed, especially well-institutionalized issues such as land use, housing and sanitation/water involve stronger urban TC, while SES-related issues with the need for novel collaborations and practices like urban greening, eco-city, eco-protection/biodiversity, and even climate change remain particularly weak-a crucial insight. Moreover, the TC components of social learning, intermediation, and multi-scalar/-level/-domain approaches, as well as supporting processes (system knowledge, foresight, experimentation) are hardly articulated overall. Strong correlations appear, however, between transformative leadership, intermediation, and empowerment, as well as between the latter, social learning and most other components. Key lessons thus underline the importance of an agency and empowerment focus in developing urban TC, addressing especially new cross-boundary challenges. While an all-encompassing approach seems unrealistic in practice, the authors suggest drawing on the urban TC framework to identify opportunities and prioritize interventions strategically. This also requires further transdisciplinary research to strengthen the usability of the framework for practitioners.

Zooming into the national context of Sweden, Borgström (2019) then explores the transformative potential of local sustainability initiatives within the highly decentralized Stockholm region. By analyzing their profile and requirements, the author reveals a diverse suite of activities which, however, display significant and persistent limitations as they largely remain disconnected across scales, sectors, actors, and/or levels. Thus, the paper reinforces the notion that the ability of motivated and engaged local actors for exploring new ways of thinking, organizing, and doing is critical, but it also highlights how such potential can become constrained by poor connectivity across multiple levels and arenas of governance, required to influence broader sustainable transformations. More attention thus needs to be paid to practical activities, processes, and structures that can promote strategic alignment and coordination between multiple actors. This includes especially the formation of intermediaries, more flexible funding programs for experimental action, and the creative exploration of alternative governance modes. Overall, the author thus recognizes a tension between the need to nurture and provide flexible spaces for community self-organization and diverse experimentation, and the requirement to forge long-term cooperation and coordination structures.

Also Wolfram (2019) analyses how urban TC is developed in a multi-level national setting. However, his comparative assessment of three South Korean cities sheds light on fundamental challenges faced in an East Asian context, taking urban regeneration policies and practices as a case in point. Similar to other countries in the region, South Korea has recently seen an urban policy U-turn promoting the revalorization of existing urban fabrics. But despite pressing needs for radical decarbonization and ecosystem restoration, the three case studies (Changwon, Gwangju, Seoul) illustrate major weaknesses across all components of urban TC and the failure to appropriately address key ecosystem implications (climate, biodiversity, water, energy, materials). This is clearly reinforced by national policy and the alignment of political priorities across levels. While in particular systems thinking, sustainability foresight, and social learning processes form key deficits, there are also drivers emerging that could have an instant capacity effect: Visioning, community empowerment, trusted intermediation, and a repositioning of local science actors could turn urban regeneration into an outstanding catalyst for developing TC. This underlines the need for national urban, research, and technology policy to provide support for integrative experimentation and collective learning processes within and across cities. The paper also stresses how the method used for assessing urban TC together with urban stakeholders could effectively contribute to build urban TC in practice.

The particular challenges involved in making urban TC inclusive and promoting social justice are addressed by Ziervogel (2019) using insights from two different urban 
contexts in South Africa. Both cases illustrate how urban poverty strongly conditions collaborative processes aimed at transformative responses to climate change induced risks, and thus requires a pro-active approach. Although cities experience increasing levels of social segregation and poverty, and although the urban poor are disproportionately exposed to global environmental change hazards, their opportunities and means to have a voice in strategic planning and policy-making processes still remain very limited. Even where the urban poor are the subject of decisions, they are seldom involved in the decision-making processes. Therefore, the author identifies an urgent need for local governments to shift their attention from the desired outcomes to the capacities and process steps that could deliver these, suggesting three approaches: (a) to understand the everyday life realities of the urban poor and foster dialogues to identify suitable interventions for transformation, (b) to support intermediaries from within the urban poor, and (c) to experiment with and learn from diverse interaction forms that support long-term inclusivity. These approaches require new types of training and skills for the actors involved, as well as novel funding and organizational structures. Further research is thus recommended to explore such inclusive governance modes and how their different features affect urban TC.

Nordström and Wales (2019) take this perspective on inclusion for transformation one step further, examining the role of children and the youth in urban planning and governance. Their paper thus looks beyond adult actors and argues that by excluding the "future generation" from current decision making, urban TC becomes fundamentally undermined. Drawing on a variety of examples from Sweden, the paper recognizes how children and the youth can have transformative impacts on built environments and urban institutions alike if proactively engaged in planning processes. Rather than forming passive recipients of change, the younger generations can thus play a crucial role as change agents in transformations. By acknowledging and fostering their agency, the authors argue, three key transformative contributions can be expected: (1) adding new values, knowledge and insights to the process, (2) shifting power relations between actors, and (3) contesting existing planning structures. Overall, the paper thus underlines the need for opening up existing institutions and practices, creating a diversity of engagement opportunities for those who will actually live the future decided upon today, and to learn from co-producing equitable and childfriendly urban environments. This analysis further highlights the relevance the urban $\mathrm{TC}$ concept attributes to empowering diversity and addressing social needs for catalyzing transformations.

Turning towards the knowledge of co-production and co-sharing processes required for developing urban TC,
Glaas et al. (2019) then discuss the potential of using novel frameworks for assessing transformative actions. Municipal councils face a considerable challenge when trying to coordinate all types of activities relevant for a climate transition, resulting in a substantial loss of change dynamic and synergies. The authors therefore developed and tested a visualization framework aimed at capturing and simplifying the diversity of ongoing and planned activities, working together with three municipalities in Sweden. The framework was applied and evaluated regarding its utility by the targeted end-users, i.e., local councilors and officials. Based on their feedback, the visualization tool was very effective for building shared system awareness by generating a comprehensive overview of current actions and identifying key challenges associated with internal processes. The authors also reflect on how the process of applying the visualization framework and realizing the evaluation workshops formed critical interventions that fostered new cross-sectoral and transdisciplinary conversations, ultimately even resulting in the conception of new internal programs and procedures. This illustrates how the capacity to effectively handle complex transformation tasks such as achieving the climate neutrality and climate proofing of a city can be enhanced through tailored assessment tools that help to co-produce system knowledge, in this case between municipal leaders and researchers.

New forms of interaction between local governments and local scientists for the development of urban TC then also form the focus of the last paper in this special issue. Withycombe Keeler et al. (2019) explore how cities and universities in the US engage in partnerships addressing urban transformations, drawing on the cases of Portland/ Oregon and Tempe/Arizona. They identify four key determinants that affect the resulting change in capacity, namely (1) the confidence built through the partnership for adopting new approaches towards sustainability and resilience, (2) novel competencies acquired by the administration for addressing complex system change, (3) the commitment obtained from a broader range of government departments and leading individuals, and (4) power shifts favoring transformation tasks within the administration and in relation to the university. The authors underline that since both city administrations and universities are relatively stable institutions, together they can provide a robust governance backbone for coping with long-term transformation challenges. Continuity of such partnerships needs to be ensured by balancing resources between partnership management and short-termed transformation projects, as well as by institutionalizing collaborations through both research and education. For this, the authors highlight six concrete ways in which universities contribute to developing TC: provide labor (students), offer feedback, provide 
input, conduct collaborative solution-oriented research, facilitate new administrative collaborations, and develop novel skills. The partnership framework thus enables to redesign existing governance arrangements, which could apparently synergize well with all the capacity development approaches addressed above.

\section{KEY FINDINGS AND ISSUES}

Despite the variety of regional and cultural contexts explored, as well as diverse urban transformation challenges studied, all seven papers coincide on four overarching key issues for the practical development of urban transformative capacity. These issues offer invaluable orientations for starting to translate what still forms a fairly abstract and dense concept into concrete intervention arenas and actionable steps. They equally set plausible priorities that can help to make process designs more efficient and effective, thus contributing to accelerate urban transformations.

\section{Foster inclusion and empowerment as elementary prerequisites for urban TC}

Across all contributions it becomes evident that open and inclusive participation and the (related) empowerment of excluded and sustainability-oriented groups represent the bottom-line necessary condition for urban TC-and should thus be the first concern when approaching its development. Even though the large sample of sustainability initiatives assessed by Castán Broto et al. (2019) indicates a comparatively higher incidence of inclusion and empowerment features, this is still at a low level (25-35\%), does not represent mainstream urban planning and policy making, and is also unlikely to encompass those requirements emphasized by the other authors in this special issue: the pro-active involvement of children and the youth (Nordström and Wales 2019), of the urban poor (Ziervogel 2019), and of progressive innovators and communities (Wolfram 2019; Borgström 2019). More often than not, conventional governance structures and decision-making practices still reinforce exclusion and disenfranchisement, even if unintentionally.

In order to "leave no one behind" (UN 2015), the process of developing urban TC must therefore nurture both the diversity and strength of alternative views arising from broader sections of society (considering especially age, gender, income, education, place-among others). In this, we argue that inclusion and empowerment are not only mechanisms for incorporating alternative values and pursuing social and environmental justice, but also vital sources of complementary knowledge required to obtain a deeper understanding of the system dynamics at play, and an effective lever for changing established practices, routines, and organizations (cf. Tengö et al. 2014). This demands to generate new opportunities, formats, and tools for engaging with a variety of stakeholders so far marginalized in decision making, and to provide the basic means (resources, skills, etc.) for them to make effective contributions. Practical measures may thus include to

- actively reach out to recognize and understand perceptions, perspectives, and everyday life worlds of the excluded;

- develop novel dialogues to jointly (re-)interpret realities and co-design interventions; and

- design, adopt, and evaluate multiple inclusion and empowerment formats to enable governance learning.

Given the widespread concerns among local government officials regarding the costs and effectiveness of conventional "participation" exercises, this may require both efforts for convincing those at the forefront to not just take action but to innovate, as well as a (re-)allocation of resources (funding, staff) that support an extended portfolio of engagement activities. It is here that inclusive governance and empowerment depends on, and can develop synergies with, other key TC components, especially transformative leadership (i.e., a change of discourse) and knowledge co-production processes (e.g., system awareness, foresight, experiments) (Frantzeskaki et al. 2018).

\section{Acknowledge, strengthen, and shape the crucial role of intermediaries and local academia}

Transformation and sustainability science scholars acknowledge for the mutual alignment occurring between multiple actors and organizations in complex system changes, suggesting the need for boundary-spanning collaboration, trust-building, goal-coordination, and knowledge co-production (Voß et al. 2006; Lang et al. 2012; Romero-Lankao et al. 2018). Formal and/or informal intermediary organizations or individual brokers which effectively promote and develop such connecting activities are therefore widely recognized as critical for urban transformations (Ernstson et al. 2010; Hamann and April 2013; Hodson et al. 2013; Pflitsch and Radinger-Peer 2018; Kivimaa et al. 2019). Moreover, especially universities have been attributed a great potential as intermediaries in urban contexts, given their multi- and interdisciplinary expertise and spatial embeddedness (Trencher et al. 2014a, b).

However, as this collection of papers has shown, substantial deficits in effective intermediation are still widespread and form a major obstacle for developing urban TC. This is clearly reflected in the very low overall incidence 
identified (7\% — cf. Castán Broto et al. 2019), as well as in the detailed qualitative accounts of disjointed, concurrent, or even conflicting stakeholder initiatives in such different national contexts as Sweden (Borgström 2019) and South Korea (Wolfram 2019). The various roles of intermediaries and their requirements are often insufficiently understood in practice, so that they turn out to be ill-equipped, mission constrained, or even entirely absent. This puts especially those actors with a path-deviant and sustainability-oriented agenda in an offside position as they remain poorly connected among themselves, to authorities at all levels, as well as to the private sector-which hinders collective reorientation and re-alignment.

We argue that this intermediation gap thus needs a dedicated response, supporting existing brokers or designing new ones with a profile tailored to a given divide: ambassadors of the urban poor (Ziervogel 2019), publiccivic hybrids for urban regeneration communities (Wolfram 2019), and new dialogue formats connecting actors across levels and domains (Borgström 2019) are pertinent examples for this. In addition, the potential of local universities needs to be unlocked, especially in the form of broader and durable partnerships that can enable a variety of intermediation and support roles (Withycombe Keeler et al. 2019), but also in more selective collaborations focused on cross-domain strategy making (Glaas et al. 2019). In these cases, local universities have become critical enablers of urban TC in that they provide novel skills and competencies while simultaneously facilitating new dialogues, thereby catalyzing a reconfiguration of urban governance structures.

\section{Challenge and reinvent urban planning as a key arena for developing urban TC}

Underlying the above concerns for engagement and intermediation, there is recognition throughout the papers of a key role in developing TC for one particular policy field: urban planning. On the one hand, this refers to its major potential as a cross-sector, multi-scalar, and place-based action domain, linked to an intrinsic aspiration for resolving goal conflicts by applying "comprehensive" approaches, and the possibility to draw in diverse resources, skills, and competencies (Wolfram 2018). These are essential features that make urban planning a critical lever for practically fostering inclusion (Nordström and Wales 2019; Ziervogel 2019), identifying and addressing the intermediation gap (Wolfram 2019; Borgström 2019), applying novel formats and methods for co-producing system knowledge (Glaas et al. 2019; Withycombe Keeler et al. 2019), and overall strengthening especially ecosystem literacy and stewardship across urban development tasks and processes (Castán Broto et al. 2019).
However, on the other hand all authors equally acknowledge how urban planning necessarily still relies on existing (i.e., path-dependent) rules and practices that tend to conform with and become instrumentalized for the currently prevailing political-economic growth paradigm, and/or remain largely confined to physical and technical dimensions of planning. There is thus an urgent need for challenging this status, we argue, and to virtually reinvent urban planning as a vital arena for developing urban TC. This requires to expose and question established ways of working, for which a closer collaboration with local universities appears to provide effective leverage (Glaas et al. 2019; Withycombe Keeler et al. 2019). Depending on the context, such a shift in planning may imply to redesign and reinvigorate current structures and processes, or to shape entirely new planning institutions with a clear focus on sustainability, transformation, and capacity developmentwhich requires both strong backing through political leadership and an articulate bottom-up planning critique. For this, we derive three strategic orientations that can strengthen the impact of urban planning on developing urban TC:

- expand multi-level, cross-scale, and cross-domain connections to shape effective systemic approaches;

- maintain and strengthen the diversity of transformative actions and TC development activities (place-based and multi-level) as key sources for learning; and

- foster synergies between implementation capability (institutionalized, centralized, resourced) and innovation capability (autonomous, decentralized, precarious) and ensure that new links are stimulating, empowering, and enabling-not conditioning, prescribing, and stifling.

\section{Foster reflexivity and collective learning through new self-assessment techniques for urban TC}

Urban transformations require collective learning within and across organizations through dedicated transdisciplinary efforts designed to co-produce a shared holistic understanding that can inform new options and priorities for action (Frantzeskaki et al. 2018). Therefore, the one process step for building urban TC that stands out from all papers is the adoption of novel frameworks and techniques for self-assessment, formal or informal, that enable to envisage, exchange, interpret, and evaluate data and knowledge held by diverse actors across domains, places, and scales. Transdisciplinary self-assessment thus proves fundamental to establish a transformation baseline and opportunity context for collective learning, and is correspondingly also applied by various authors-be that in the form of a policy visualization and assessment tool (Glaas 
et al. 2019), through joint mapping of initiatives and governance structures (Borgström 2019), in a differential assessment of transformative capacity by stakeholders and researchers (Wolfram 2019), or the various techniques used in the context of city-university partnerships (Withycombe Keeler et al. 2019). Such forms of self-assessment are, however, the exception, and thus need more targeted support, e.g., through research policy and new regulation.

\section{CONCLUSIONS AND OUTLOOK}

Returning to our guiding questions, the above discussion provides a number of responses that can inform the conceptual debate on urban transformative capacity, as well as the design and implementation of practical approaches for its development. Yet, it also reflects issues that will have to be addressed by future research. Both are briefly synthesized in the following:

First of all, starting from the urban TC framework (Wolfram 2016), we asked which components appear to be critical and how they interact with each other-in order to derive priorities and strategies for intervention. While the core factors are basically reconfirmed, the insights provided by the papers put much greater emphasis on the central agency axis and how to initiate its articulation: from the focus on inclusion and empowerment as a bottomline condition to the role of urban planning, local academia, and intermediaries in (re-)shaping inclusive and multiform governance arrangements: These appear to offer key entry points for developing urban TC from scratch and anchored in particular urban places.

In turn, the leverage of transformative leadership as a crucial form of agency that supports these activities is acknowledged, but analyzed empirically in less detail. While leadership inevitably remains an uncertain factor when it comes to actively shaping it, some propositions are made in this direction, considering, for example, dedicated training or the strategic assignment of new leadership roles. Further scrutiny is, however, required regarding common factors that shape transformative leadership, and how it interacts with other agency components.

Also social learning is underlined repeatedly as a central driver for urban TC development, as illustrated by the various approaches for self-assessment described. These (can) connect distributed forms of agency to the processes of creating shared system awareness, sustainability foresight, practical experimentation, and innovation embedding. However, since all cases analyzed represent early stages of transformations (i.e., pre-development), deeper insights regarding feedbacks between components (e.g., from experiments), synergies and conflicts (e.g., between diverse governance arenas and experiments), and the social learning and political dynamics these imply are still missing. Correspondingly, research on later transformation stages would also allow to critically explore the modification of legitimacy and accountability structures involved in the development of urban TC (cf. Miller and Wyborn 2018).

Second, we were interested in how to assess urban TC consistently in different world regions, countries, and places. Here the findings and discussions suggest that the urban TC framework provides a relevant and comprehensive set of variables for this. Since the purpose of such assessment would be less to benchmark (which is strongly constrained by differences in ecological, cultural, and socio-economic conditions), propositions made for further refinement underline the need for transdisciplinarity rather than for consistent indicator sets and measurements. Consistency therefore matters within a given context and needs to be ensured by the stakeholders involved, but decisive for urban TC is the knowledge co-production process through which this is achieved, ensuring that new understandings are actually adopted and shared by the actors involved. Nevertheless, contrasting the papers also reflects the need for clarifying at what point in time an assessment is carried out (transformation phases), and what this implies for particular outcomes targeted (e.g., justice, stewardship, exnovation, innovation). In this regard, there is little orientation available so far, that is future research needs to provide insights into the temporal dynamics of urban TC development, relating its components and their interactions to different transformative outcomes.

Finally, we also asked how a focus on urban TC can contribute to purposefully shape urban transformations. Taken together, the papers provide diverse empirical evidence for the utility of an urban TC lens to identify and create conditions for making radical systemic urban change possible and more likely. There is, however, no claim that such change will occur necessarily, or necessarily in the direction of sustainability: Understanding and developing TC forms an approach to urban transformations that relies on emergence as a basic property of complex adaptive systems, and as such rejects attempts of management and control. Similarly, even though sustainability values and principles do inform its components, the actual formation of urban TC always remains subject to contestation and could also happen in pursuit of divergent normative orientations.

As discussed above, current deficits in urban TC are outstanding, making its development a high priority for all stakeholders, and for policy in particular: Dedicated guidance and support are needed for building urban TC for sustainability, in which research policy should play a prominent role to leverage the involvement of local academia, and spatial planning policy to foster inclusion, intermediation, system thinking, and place-based 
approaches. The seven papers offer concrete lessons and guidance for how to apply an urban TC perspective in practice. Future research should, however, try to obtain complementary insights into how such multi-agency and co-production processes emerge and unfold in different global contexts, urban domains, and places, how they are enabled or constrained by particular institutions and spatial-material configurations, and with what outcomes in terms of transformation. Transdisciplinary approaches that fully incorporate the views and insights of diverse urban stakeholders will be indispensable for this-especially as they simultaneously contribute to practically develop urban transformative capacity.

Acknowledgements We would like to thank Bo Söderström for his effective support throughout the entire process of editing this issue. The contributions by Sara Borgström were financially supported by the School of Architecture and Built Environment at the Royal Institute of Technology, Stockholm.

\section{REFERENCES}

Acuto, M., E. Robin, and S. Lane. 2018. Interim report of the Nature Sustainability expert panel. UCL city leadership lab report. London: University College London.

Ardoin, N.M., R.K. Gould, E. Kelsey, and P. Fielding-Singh. 2015. Collaborative and Transformational Leadership in the Environmental Realm. Journal of Environmental Policy \& Planning 17: 360-380. https://doi.org/10.1080/1523908x.2014.954075.

Avelino, F. 2017. Power in sustainability transitions: Analysing power and (dis)empowerment in transformative change towards sustainability. Environmental Policy and Governance 27: 505-520. https://doi.org/10.1002/eet.1777.

Avelino, F., and J. Rotmans. 2011. A dynamic conceptualization of power for sustainability research. Journal of Cleaner Production 19: 796-804. https://doi.org/10.1016/j.jclepro.2010.11.012.

Avelino, F., and J.M. Wittmayer. 2016. Shifting power relations in sustainability transitions: A multi-actor perspective. Journal of Environmental Policy \& Planning 18: 628-649. https://doi.org/ 10.1080/1523908x.2015.1112259.

Borgström, S. 2019. Balancing diversity and connectivity in multilevel governance settings for urban transformative capacity. Ambio. https://doi.org/10.1007/s13280-018-01142-1.

Castán Broto, V., G. Trencher, E. Iwaszuk, and L. Westman. 2019. Transformative capacity and local action for urban sustainability. Ambio. https://doi.org/10.1007/s13280-018-1086-z.

Chapin, F.S., S.R. Carpenter, G.P. Kofinas, C. Folke, N. Abel, W.C. Clark, P. Olsson, D.M.S. Smith, et al. 2010. Ecosystem stewardship: Sustainability strategies for a rapidly changing planet. Trends in Ecology \& Evolution 25: 241-249.

CitiesIPCC. 2018. Global research and action agenda on cities and climate change science. Cities and Climate Change Science Conference.

Coleman, W.D., and C. Chiasson. 2002. State power, transformative capacity and adapting to globalization: An analysis of French agricultural policy, 1960-2000. Journal of European Public Policy 9: 168-185.

Dolata, U. 2013. The transformative capacity of new technologies: A theory of sociotechnical change. Routledge Advances in Sociology v. 96. New York: Routledge.
Elmqvist, T., X. Bai, N. Frantzeskaki, C. Griffith, D. Maddox, T. McPhearson, S. Parnell, P. Romero-Lankao, et al. (eds.). 2018. Urban planet: Knowledge towards Sustainable Cities, 1st ed. Cambridge: Cambridge University Press. https://doi.org/10. 1017/9781316647554.

Ernstson, H., S. Barthel, E. Andersson, and S. Borgström. 2010. Scale-crossing brokers and network governance of urban ecosystem services: The case of Stockholm. Ecology and Society 15: 28.

Folke, C., S. Carpenter, T. Elmqvist, L. Gunderson, C.S. Holling, and B. Walker. 2002. Resilience and sustainable development: Building adaptive capacity in a world of transformations. Ambio 31: 437-440.

Folke, C., J. Colding, and F. Berkes. 2003. Synthesis: Building resilience for adaptive capacity in social-ecological systems. Navigating social-ecological systems: Building resilience for complexity and change, 352-387. Cambridge: Cambridge University Press.

Frantzeskaki, N., V.C. Broto, and L. Coenen (eds.). 2017. Urban sustainability transitions., Routledge Studies in Sustainalbility Transitions 1 New York: Routledge.

Frantzeskaki, N., K. Hölscher, M. Bach, and F. Avelino (eds.). 2018. Co-creating sustainable urban futures. A primer on applying transition management in cities. Future City 11. Cham: Springer.

Geels, F.W., R. Kemp, G. Dudley, and G. Lyons (eds.). 2012. Automobility in transition? A socio-technical analysis of sustainable transport., Routledge Studies in Sustainability Transitions 2 New York: Routledge.

Gillard, R., A. Gouldson, J. Paavola, and J. Van Alstine. 2016. Transformational responses to climate change: Beyond a systems perspective of social change in mitigation and adaptation. Wiley Interdisciplinary Reviews 7: 251-265. https://doi.org/10.1002/ wcc. 384.

Glaas, E., M. Hjerpe, S. Storbjörk, T.-S. Neset, A. Bohman, P. Muthumanickam, and J. Johansson. 2019. Developing transformative capacity through systematic assessments and visualization of urban climate transitions. Ambio. https://doi.org/10.1007/ s13280-018-1109-9.

Griffith, R. 2014. Transformative capacity. Resource Sheet RS 6. Sydney/Beechworth: Australian Resilience Center.

Grillitsch, M. 2017. Transformation Capacity of the Innovative Entrepreneur: On the interplay between social structure and agency. 2017/02. Papers in Innovation Studies. Lund: CIRCLE, Lund University.

Grimm, N.B., S. Faeth, N.E. Golubiewski, C.L. Redman, J. Wu, X. Bai, and J.M. Briggs. 2008. Global change and the ecology of cities. Science 317: 756-760.

Groffman, P.M., M.L. Cadenasso, J. Cavender-Bares, D.L. Childers, N.B. Grimm, J.M. Grove, S.E. Hobbie, L.R. Hutyra, et al. 2017. Moving towards a new urban systems science. Ecosystems 20: 38-43. https://doi.org/10.1007/s10021-016-0053-4.

Gunderson, L.H., and C.S. Holling (eds.). 2002. Panarchy: Understanding transformations in human and natural systems. Washington, DC: Island Press.

Halpin, D., and C. Daugbjerg. 2008. Associative deadlocks and transformative capacity: Engaging in Australian organic farm industry development. Australian Journal of Political Science 43: 189-206.

Hamann, R., and K. April. 2013. On the role and capabilities of collaborative intermediary organisations in urban sustainability transitions. Journal of Cleaner Production 50: 12-21.

Hansen, T., and L. Coenen. 2014. The geography of sustainability transitions: Review, synthesis and reflections on an emergent research field. Environmental Innovation and Societal Transitions.. https://doi.org/10.1016/j.eist.2014.11.001. 
Healey, P. 1998. Building institutional capacity through collaborative approaches to urban planning. Environment and Planning A 30: 1531-1546.

Heyen, D., L. Hermwille, and T. Wehnert. 2017. Out of the Comfort Zone! Governing the exnovation of unsustainable technologies and practices. GAIA: Ecological Perspectives for Science and Society 26: 326-331.

Hodson, M., S. Marvin, and H. Bulkeley. 2013. The intermediary organisation of low carbon cities: a comparative analysis of transitions in Greater London and Greater Manchester. Urban Studies 50: 1403-1422.

Holling, C.S. 1973. Resilience and stability of ecological systems. Annual Review of Ecology and Systematics 4: 1-23.

Hölscher, K., N. Frantzeskaki, and D. Loorbach. 2018. Steering transformations under climate change: Capacities for transformative climate governance and the case of Rotterdam, the Netherlands. Regional Environmental Change. 5: 5-6.

Innes, J., and D. Booher. 2003. The Impact of Collaborative Planning on Governance Capacity. In . IURD Working Paper Series. Baltimore: Institute of Urban \& Regional Development.

IPCC. 2018. Global Warming of $1.5^{\circ} \mathrm{C}$. Special Report. Intergovernmental Panel on Climate Change.

Iwaniec, D., E. Cook, O. Barbosa, and N. Grimm. 2019. The framing of urban sustainability transformations. Sustainability 11: 573.

Kivimaa, P., W. Boon, S. Hyysalo, and L. Klerkx. 2019. Towards a typology of intermediaries in sustainability transitions: A systematic review and a research agenda. Research Policy 48: 1062-1075.

Kuenkel, P. 2019. Stewarding sustainability transformations: An emerging theory and practice of SDG implementation. Berlin: Springer.

Lang, D.J., A. Wiek, M. Bergmann, M. Stauffacher, P. Martens, P. Moll, M. Swilling, and C.J. Thomas. 2012. Transdisciplinary research in sustainability science: Practice, principles, and challenges. Sustainability Science 7: 25-43. https://doi.org/10. 1007/s11625-011-0149-x.

Lawrence, T.B., R. Suddaby, and B. Leca (eds.). 2009. Institutional work: Actors and agency in institutional studies of organizations. New York: Cambridge University Press.

Marshall, N.A., S.E. Park, W.N. Adger, K. Brown, and S.M. Howden. 2012. Transformational capacity and the influence of place and identity. Environmental Research Letters 7: 034022. https://doi. org/10.1088/1748-9326/7/3/034022.

Metzger, J., L. Soneryd, and K. Tamm Hallström. 2017. 'Power' is that which remains to be explained: Dispelling the ominous dark matter of critical planning studies. Planning Theory 16: 203-222. https://doi.org/10.1177/1473095215622502.

Miller, C.A., and C. Wyborn. 2018. Co-production in global sustainability: Histories and theories. Environmental Science \& Policy. https://doi.org/10.1016/j.envsci.2018.01.016.

Moore, M.-L., O. Tjombo, E. Enfors, C. Knapp, J. Hodbod, J.A. Baggio, A. Norström, P. Olsson, et al. 2014. Studying the complexity of change: Toward an analytical framework for understanding deliberate social-ecological transformations. Ecology and Society 19: 54.

Moore, M.-L., P. Olsson, W. Nilsson, L. Rose, and F.R. Westley. 2018. Navigating emergence and system reflexivity as key transformative capacities: Experiences from a Global Fellowship program. Ecology and Society 23: 2.

Moulaert, F., F. Martinelli, E. Swyngedouw, and S. González. 2005. Towards alternative model(s) of local innovation. Urban Studies 42: 1969-1990.

Murdoch, J. 2006. Post-structuralist geography: A guide to relational space. London: SAGE.

Newton, P., D. Meyer, and S. Glackin. 2017. Becoming urban: Exploring the transformative capacity for a suburban-to-urban transition in Australia's low-density cities. Sustainability 9: 1718.

Nordström, M., and M. Wales. 2019. Enhancing urban transformative capacity through children's participation in planning. Ambio. https://doi.org/10.1007/s13280-019-01146-5.

O’Brien, K. 2012. Global environmental change II: From adaptation to deliberate transformation. Progress in Human Geography 36: 667-676. https://doi.org/10.1177/0309132511425767.

Olsson, P., C. Folke, and T. Hahn. 2004. Social-ecological transformation for ecosystem management the development of adaptive co-management of a wetland landscape in Southern Sweden. Ecology \& Society 9: 4.

Olsson, P., Ö. Bodin, and C. Folke. 2010. Building transformative capacity for ecosystem stewardship in social-ecological systems. In Adaptive capacity and environmental governance, ed. D. Armitage and R. Plummer, 263-285. Berlin: Springer.

Pflitsch, G., and V. Radinger-Peer. 2018. Developing boundaryspanning capacity for regional sustainability transitions: A comparative case study of the Universities of Augsburg (Germany) and Linz (Austria). Sustainability 10: 918.

Rauschmayer, F., T. Bauler, and N. Schäpke. 2015. Towards a thick understanding of sustainability transitions: Linking transition management, capabilities and social practices. Ecological Economics 109: 211-221.

Romero-Lankao, P., H. Bulkeley, M. Pelling, S. Burch, D.J. Gordon, J. Gupta, C. Johnson, P. Kurian, et al. 2018. Urban transformative potential in a changing climate. Nature Climate Change 8: 754-756.

Sewell, W. 1992. A theory of structure: Duality, agency, and transformation. American Journal of Sociology 28: 1-29.

Tàbara, J., F. Cots, S. Pedde, K. Hölscher, K. Kok, A. Lovanova, T. Capela Lourenço, N. Frantzeskaki, et al. 2018. Exploring institutional transformations to address high-end climate change in Iberia. Sustainability 10: 161. https://doi.org/10.3390/ su10010161.

Tengö, M., E.S. Brondizio, T. Elmqvist, P. Malmer, and M. Spierenburg. 2014. Connecting diverse knowledge systems for enhanced ecosystem governance: The multiple evidence base approach. Ambio 43 (5): 579-591.

Thrift, N.J. 1996. Spatial formations. Theory, Culture \& Society. London: Sage.

Trencher, G., M. Yarime, K.B. McCormick, C.N.H. Doll, and S.B. Kraines. 2014a. Beyond the third mission: Exploring the emerging university function of co-creation for sustainability. Science and Public Policy 41: 151-179.

Trencher, Gregory, X. Bai, J. Evans, K. McCormick, and M. Yarime. 2014b. University partnerships for co-designing and co-producing urban sustainability. Global Environmental Change 28: 153-165. https://doi.org/10.1016/j.gloenvcha.2014.06.009.

UN. 2015. Transforming our world: The 2030 Agenda for Sustainable Development.

UN. 2016. New Urban Agenda.

Un, D.E.S.A. 2018. 2018 revision of World Urbanization Prospects. New York: United Nations Department of Economic and Social Affairs.

van Driel, H., and J. Schot. 2005. Radical innovation as a multilevel process: Introducing floating grain elevators in the port of Rotterdam. Technology and Culture 46: 51-76.

Voß, J.-P., D. Bauknecht, and R. Kemp (eds.). 2006. Reflexive governance for sustainable development. Cheltenham: Edward Elgar.

Walker, B., C.S. Holling, S.R. Carpenter, and A. Kinzig. 2004. Resilience, adaptability and transformability in social-ecological systems. Ecology and Society 9: 5.

Westley, F., P. Olsson, C. Folke, T. Homer-Dixon, H. Vredenburg, D. Loorbach, J. Thompson, M. Nilsson, et al. 2011. Tipping toward 
sustainability: Emerging pathways of transformation. Ambio 40: 762-780.

Westley, F.R., O. Tjornbo, L. Schultz, P. Olsson, C. Folke, B. Crona, and Ö. Bodin. 2013. A theory of transformative agency in linked social-ecological systems. Ecology and Society. https://doi.org/ 10.5751/es-05072-180327.

Wilson, S., L.J. Pearson, Y. Kashima, D. Lusher, and C. Pearson. 2013. Separating adaptive maintenance (resilience) and transformative capacity of social-ecological systems. Ecology and Society. https://doi.org/10.5751/es-05100-180122.

Withycombe Keeler, L., F. Beaudoin, A. Wiek, B. John, A.M. Lerner, R. Beecroft, K. Tamm, A. Seebacher, et al. 2019. Building actorcentric transformative capacity through city-university partnerships. Ambio. https://doi.org/10.1007/s13280-018-1117-9.

Wolfram, M. 2016. Conceptualizing urban transformative capacity: A framework for research and policy. Cities 51: 121-130.

Wolfram, M. 2018. Urban planning and transition management: Rationalities, instruments and dialectics. In Co-creating sustainable urban futures, ed. N. Frantzeskaki, M. Bach, K. Hölscher, and F. Avelino, 103-125. New York: Springer.

Wolfram, M. 2019. Assessing transformative capacity for sustainable urban regeneration: A comparative study of three South Korean cities. Ambio. https://doi.org/10.1007/s13280-018-1111-2.

Wolfram, M., N. Frantzeskaki, and S. Maschmeyer. 2016. Cities, systems and sustainability: Status and perspectives for research on urban transformations. Current Opinion in Environmental Sustainability. https://doi.org/10.1016/j.cosust.2017.01.014.

Ziervogel, G. 2019. Building transformative capacity for adaptation planning and implementation that works for the urban poor: Insights from South Africa. Ambio. https://doi.org/10.1007/ s13280-018-1141-9.

Ziervogel, G., A. Cowen, and J. Ziniades. 2016. Moving from adaptive to transformative capacity: Building foundations for inclusive, thriving, and regenerative urban settlements. Sustainability 8: 955.

\section{Publisher's Note}

Springer Nature remains neutral with regard to jurisdictional claims in published maps and institutional affiliations.

\section{AUTHOR BIOGRAPHIES}

Marc Wolfram $(\square)$ is an Associate Professor for urban sustainability and transformation at SKKU (Sungkyunkwan University). His research focuses on sustainability innovations in urban governance, planning, policy and design, targeting social-ecological-technological system change. His academic background is interdisciplinary and combines engineering and the social sciences.

Address: Urban Transformations Lab, Department of Architecture, Sungkyunkwan University, 2066 Seobu-ro, Suwon 16419, South Korea.

e-mail: marcwolfram@gmail.com; wolfram@skku.edu

Sara Borgström is an Assistant Professor at the Royal Institute of Technology in Stockholm. Her research interests include urban sustainable development with a special focus on the integration of environmental, ecological, and green dimensions into urban landscape governance and co-creation processes linking research to policy and practice.

Address: Division of Strategic Sustainability Studies (3S), Department of Sustainable Development, Environmental Science and Engineering (SEED), KTH (Royal Institute of Technology), 10044 Stockholm, Sweden.

e-mail: sara.borgstrom@abe.kth.se

Megan Farrelly is an Associate Professor in the School of Social Sciences at Monash University. Her research is situated at the intersection of environmental studies, sustainability transitions, and experimentation. Framed through urban governance and policy, her research explores the different forces shaping the trajectory of sustainability innovation and experimentation, particularly within water and energy domains, with the aim of influencing future policy and practice interventions.

Address: Human Geography, School of Social Sciences, Monash University, 20 Chancellors Walk, Building 11, W819, Clayton, VIC 3800, Australia.

e-mail: megan.farrelly@monash.edu 